\title{
Technovigilance and risk management as tools to improve patient safety in Colombian health care institutions
}

\author{
A.M. Sánchez ${ }^{1}$, A. Betancourt ${ }^{1}$, C. Mantilla ${ }^{1}$, A.M. Gonzalez-Vargas ${ }^{1,2, \psi}$ \\ ${ }^{1}$ Universidad Autónoma de Occidente \\ ${ }^{2}$ Grupo de Investigación en Ingeniería Biomédica G-BIO
}

\begin{abstract}
This paper presents the results of a survey about technovigilance carried out in 21 clinical institutions in southwest Colombia. It also provides an analysis of how these programs take into account different risk management methodologies in order to create awareness of the importance of patient safety in all staff members and improve quality of the health services provided.

Keywords - Technovigilance, vigilance, risk management, patient safety, medical devices.

\section{La Tecnovigilancia y la Gestión de Riesgos como herramientas Para MEJORAR LA SEGURIDAD DE LOS PACIENTES EN LAS INSTITUCIONES DE SALUD COLOMBIANAS}

Resumen - Este trabajo presenta los resultados de una encuesta acerca de la tecnovigilancia realizada en 21 instituciones de salud del suroeste de Colombia. Adicionalmente proporciona un análisis de cómo estos programas consideran diferentes metodologías de manejo de riesgos para crear conciencia en todos los empleados de la importancia de la seguridad de los pacientes y así mejorar la calidad de los servicios de salud prestados.

Palabras clave - Tecnovigilancia, vigilancia, manejo del riesgo, salud del paciente, dispositivos médicos. 


\section{A Tecnovigilância e a Gestão de Riscos como Ferramentas para Melhorar a Segurança dos Pacientes nas Instituições de Saúde COLOMBianas}

Resumo-Este trabalho apresenta os resultados de uma pesquisa a respeito da vigilância tecnológica levada a cabo em 21 instituições de saúde do sudoeste da Colômbia. Adicionalmente proporciona uma análise de como estes programas consideram diferentes metodologias do controle de riscos para criar consciência em todos os empregados da importância da segurança dos pacientes e assim melhorar a qualidade dos serviços de saúde emprestados.

Palavras-chave - Tecnovigilância, vigilância, controle do risco, saúde do paciente, dispositivos médicos

\section{INTRODUCTION}

Th hospital institutions, an adequate risk management improves the quality of the service provided to the patient and creates safety conditions for the patients as well as for the clinical, technical and administrative staff working in the institution. The lack of methodologies for managing, identifying, evaluating and controlling risk by the staff who handles biomedical equipment is a cause of recurrence of accidents related to such equipment and, in order to reduce this failure, it is necessary to have a multidisciplinary group that trains the staff in the identification of the basic risks of the equipment, proposing controls and solutions to common problems.

The use of medical devices is inevitably associated with the possibility of accidents that can cause minor or serious injuries to patients and equipment operators. For this reason, the current legislation seeks the active participation of health service providers, independent professionals, manufacturers of medical devices and the community in general, with the purpose of identifying and reporting adverse situations and being able to generate preventive or corrective actions in order to minimize future risks. These activities are part of the Medical Device Vigilance Systems, often called Technovigilance programs in Latin America

The purpose of this paper is to present important elements to be taken into account for the adequate application of a risk management methodology that takes into account the information provided by the technovigilance program, starting with an analysis of the implementation of these programs in several clinical institutions in the southwestern region of Colombia. The paper is organized as follows: Section 2 presents the theoretical concepts needed to address the problem, section 3 describes the methodology used for the surveys, section 4 presents the most relevant results of the survey and analyzes them, sections 5 and 6 provide a general discussion and conclusions about the observed results.

\section{Conceptual Framework}

Before addressing the survey and its corresponding analysis, a brief review of the most relevant concepts will be made.

\section{A. Technovigilance}

Also called Techno-surveillance or Medical Device Vigilance, the Technovigilance is the set of preventive and corrective measures adopted by clinical institutions in the different management processes of biomedical technologies in order to minimize the risks associated with the use of such technologies [1].

\section{B. Risk management}

Risk management is the systematic process of identifying, evaluating, reducing or eliminating and communicating the likelihood of a materialized risk [2]. This process requires that decisions be made taking into account safety estimates and involves technical, psychological and social aspects. Risk in clinical institutions can affect the patient's health as well as that of the staff or the people who visits the patient. A large number of these risks are inherent in the use of biomedical technology and, because of this, biomedical equipment in Colombia has been categorized (following European system [3]) as Class I (low risk), Class IIA (moderate risk), Class IIB (high risk) and Class III (very high risk).

Risk management in organizations is covered by the ISO 31000 standard [4], which allows the identification of risks in different disciplines, regardless of the size of the organization, and structures the context necessary to identify the risks, evaluate them and analyze their treatment.

In the health care field, it is also important to follow the ISO 14971 standard [5], which establishes the risk management in medical devices to be contemplated by the manufacturer. This standard can be applied at all stages 
of life of the biomedical device, and requires maintaining an updated resume, together with the development of all known or foreseeable hazards.

\section{Failure Modes and Effects Analysis (FMEA)}

It is an analysis procedure that classifies potential failures according to their severity or the effect produced [6]. It is commonly used for risk management associated with biomedical technology in various phases of the device life cycle. The causes of the failures can be any errors or defects in the processes or design, especially those that affect the patients, and can be potential or real. The term effects analysis refers to the study of the consequences of such failures. FMEA can provide an analytical approach by managing the potential failure modes and their associated causes. Risk priority is an important part of the criteria for selecting an action plan against failure modes, and helps in the evaluation of these actions. To calculate this priority, three variables are used: Severity evaluates the damage to the patient, Occurrence evaluates the probability that the failure will happen, Detectability evaluates the probability of detecting the failure before it affects the patient. Each variable is assigned a value between one (lowest risk) and five (highest risk), and then the risk priority number is calculated as follows:

$\mathrm{RPN}=$ Severity $\mathrm{x}$ Occurrence $\mathrm{x}$ Detectability
The following table lists the levels of risk and impact according to the qualification of the priority level.

Table 1. Levels of Risk Classification

\begin{tabular}{lll}
\hline & Levels of Risk Classification \\
\hline Classification & Category & Criteria \\
\hline$(14-24)$ & Significant & $\begin{array}{c}\text { It can result in death, } \\
\text { function or structure loss for } \\
\text { the patient or user. }\end{array}$ \\
\hline$(08-13)$ & Moderate & $\begin{array}{c}\text { It can result in a reversible } \\
\text { injury or small injury to the } \\
\text { patient or user. }\end{array}$ \\
& & \\
$(02-08)$ & Insignificant & $\begin{array}{c}\text { It causes no injury or an } \\
\text { insignificant injury to the } \\
\text { patient or user. }\end{array}$ \\
\hline
\end{tabular}

After implementing the actions in the design or process, the risk priority number must be checked again to confirm the improvements. These tests are usually represented graphically for simpler viewing. Whenever changes are made to a process or design, the FMEA should be updated.

\section{ORGANISATIONAL ACCIDENT CAUSATION MODEL}
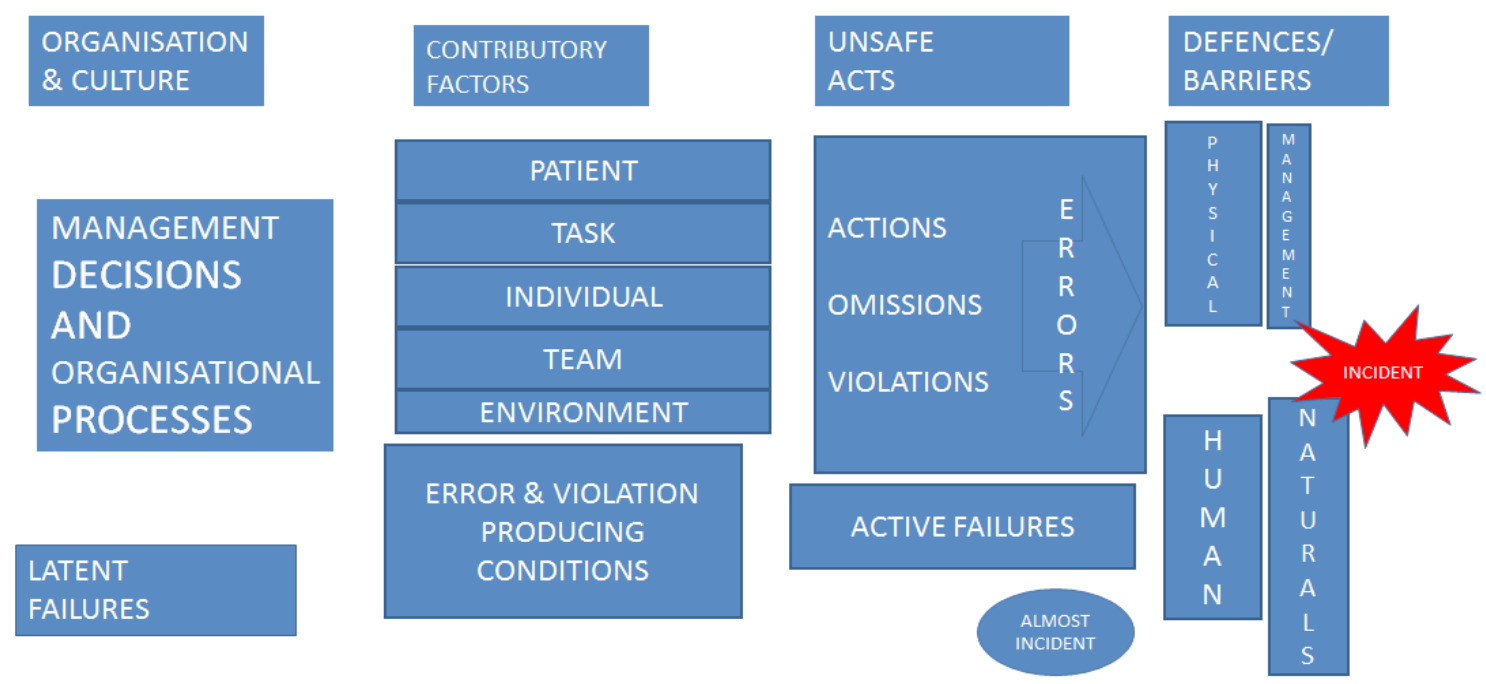

Fig 1. Organizational Accident Causation Model [7] 


\section{London Protocol}

It is a practical guide for risk managers and other professionals related to the topic. It is a revised and developed version taking into account the experience in accident investigation in the health sector and other industries that have advanced in their prevention [7]. Its purpose is to facilitate the investigation of clinical incidents, so it goes beyond simply identifying the fault or finding the person responsible for it. In fact, what is sought is an analysis that allows to discover the series of events concatenated that lead to the incident, carrying out a systematic investigation process in an open environment, which does not pretend to make guilt assignments.

The theory that supports the protocol and its applications originates in fields such as aviation and the oil and nuclear industries, where accident investigation is an established routine. Some of the methods of analysis used in these sectors have been adopted for use in clinical and care settings. The basis of the protocol is the organizational model of accidents proposed by James Reason, also known as Swiss cheese model.

According to this model, the conditions for an adverse event begin from the decisions of the high management levels and from there down through the different departmental channels, finally affecting the working sites. During the analysis, each of these elements should be considered separately and in detail, starting with unsafe actions (actions and omissions with potential to cause an adverse event) and barriers that failed, finally reaching the organizational processes and practices. The next thing is to consider the overall institutional context and circumstances in which errors known as contributory factors were committed. At the head of these contributory factors are the health conditions of the patient as well as his personality, language, religious beliefs and psychological problems.

The research and analysis process is fairly standardized and has been designed for use both in cases of minor incidents, and serious adverse events and can run either by a person or by a team of experts. The decision will be made depending on the severity of the incident, the resources available and the learning potential of the institution.

\section{E. Colombian Technical Guide 45 (GTC 45)}

This guide defines the principle, method and criteria for the identification of hazards and risk assessment in the field of occupational safety and health, which allows for a risk matrix association in which a diagnosis is made of the hazard conditions that could materialize a risk within the daily practices of the use of biomedical technology [4].

Within the implementation criteria, the adjustment to the needs of each institution, the type of activities to be performed and the resources available for control are highlighted.

\section{INCIDENT INVESTIGATION (ADVERSE ERRORS \& EVENTS)}

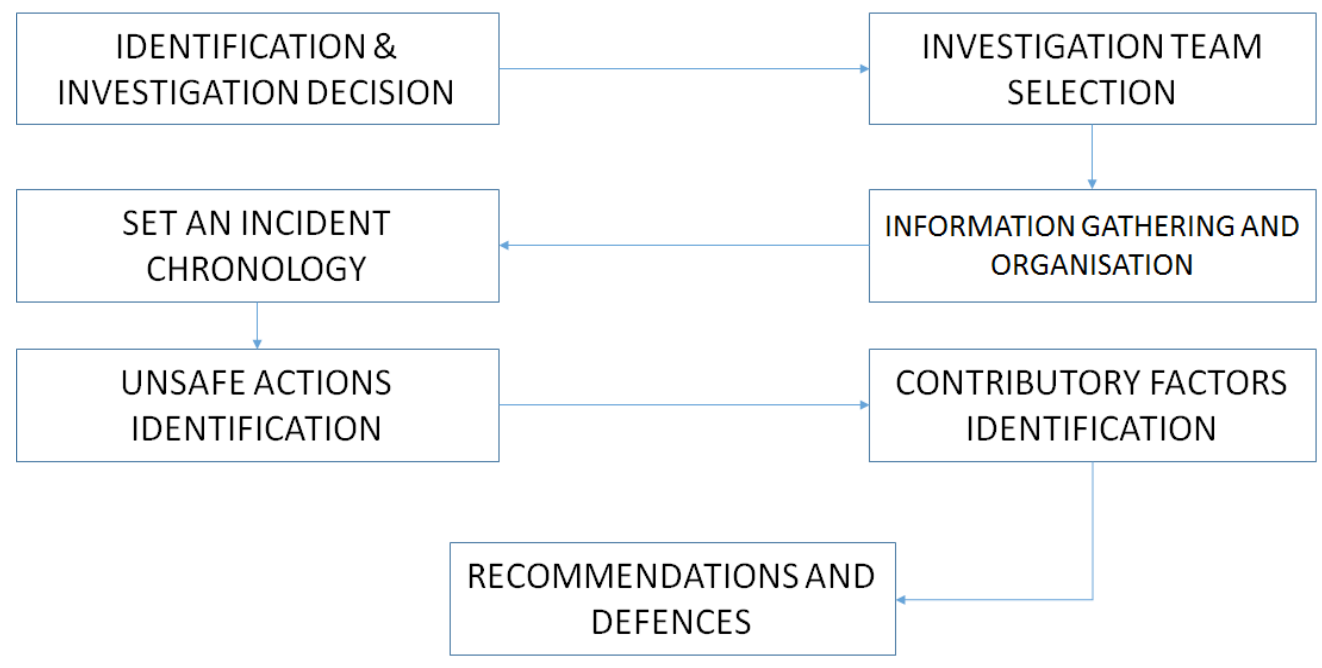

Fig 2. Incident investigation process 
In addition, it manages the conditions and / or risk factors that allow a tangibility of the risk, complementing its management with the elaboration of controls in its different categories and that are applicable to the different types of methodologies described so far.

The priority level allows identifying the type of control applicable to the identified risk, always prioritizing risk elimination, second degree substitution, engineering control for locative control and, ultimately, the use of personal protection elements by the user.

\section{Methodology}

In order to know about the practices of technovigilance and clinical risk management in the southwestern región of Colombia, a survey with 16 questions was answered by officials of 21 clinical institutions belonging to the Southwestern Node of the Colombian Clinical Engineering Network. In this document we will present the most relevant results obtained in these surveys and we will confront these results with the practices suggested by the guides and documents that address these issues at the international level.

\section{RESULTS}

At present, when it comes to technovigilance in clinical institutions, it is important not only to include a reactive approach (based on reports of adverse events and incidents), but also to focus on prevention (proactive technovigilance), carrying out a timely risk management that allows to work with greater effectiveness in relation to the safety of the patient and the personnel in charge of operating the medical devices.

Based on this premise, the survey was carried out to make a general diagnosis of how technovigilance programs are being carried out in these two aspects, with emphasis on risk management systems.

First, it was asked whether the institution had a technovigilance program in accordance with Resolution 4816 of 2008 . The majority gave an affirmative answer, with the exception of one institution out of the 21 asked. It was also asked about the profesional background of the technovigilance representative, finding out that this role is usually carried out by a biomedical engineer (19 institutions), followed by a pharmaceutical chemist (1 institution). We can see that the guidances [1] of INVIMA (Colombian National Institute for Medicines Vigilance) are being followed, where it is established that this position is fulfilled by a competent professional in the subject.
Institutions were also asked about their reporting practices. With the exception of one institution, the majority affirms that if it is a serious event or incident, the report is made before 72 hours, and if it is not serious, the report is made every 3 months. This also shows compliance with what was established by INVIMA in Resolution 4816 of 2008 [9].

Constant training is a key strategy for keeping the staff up to date with the policies and procedures of the institutional programs. In this sense, we asked the participating institutions how many times they had training sessions in technovigilance during the last year. The results are shown in Fig. 3. It is interesting to note that about half of the institutions have performed between zero and three trainings in the last year, corresponding to a frequency of four months or less, while another important percentage $(38 \%)$ performs more than ten trainings per year, which indicates an approximately monthly frequency, and which is related in several cases with the entry of new staff to the institution.

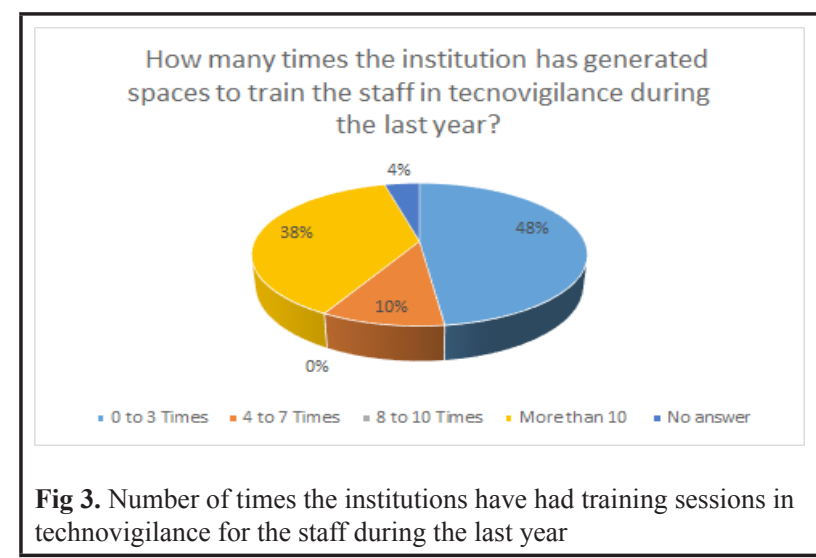

Regarding the risk management of medical devices, we asked what methodology is currently used for this purpose. A large number of institutions use the London protocol (17 institutions), followed by the FMEA methodology (7 institutions), GTC 45 (1) and Cause Effect (1) [10]. This is shown in Fig. 4. In six institutions, two methodologies for risk management are used concurrently. In all these cases the prevalent methodology is the London Protocol. This coexistence may be due to the fact that the institution is currently switching from one methodology to another, based on INVIMA's guidances, which in 2012 determined that the FMEA methodology is the most recommended. This was determined by a study which used two devices (Infusion Pump and Central Venous Catheter) and a pilot test performed in five high complexity health care institutions, in the cities of Bogotá, Medellín, Cali and Barranquilla [11]. 


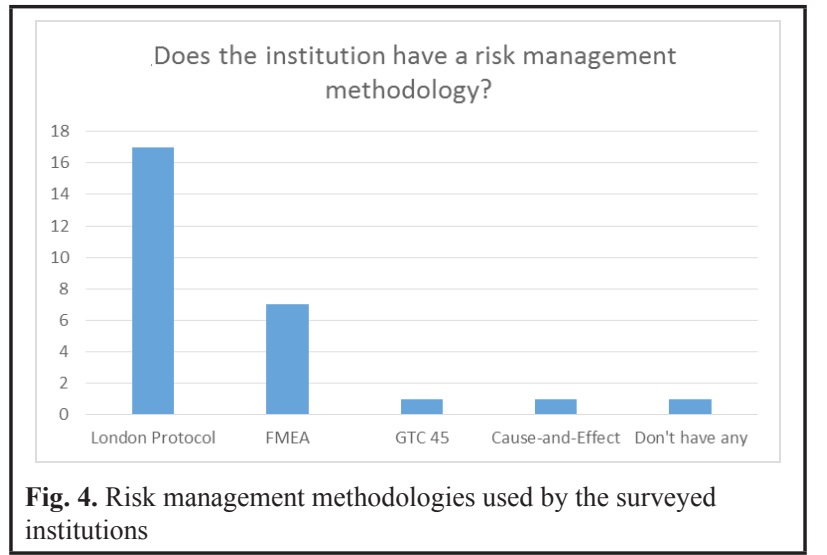

One of the questions that caused particular interest in the technovigilance survey whether the risk management methodologies in the different institutions were updated every time a serious incident or event occurs.

For this question the affirmative and negative answers are given in a very similar percentage as can be observed in Fig. 5, which may be due to the fact that the answerers do not handle the same considerations. For example, in $48 \%$ of the cases there is no correlation between the criteria for updating the selected methodologies and the incidence of serious events. However, we can not affirm that updating is not done in other circumstances, for example when identifying a new technology, with the incorporation of new services, etc. Therefore, in this aspect, it would be necessary to carry out a deeper investigation that allows to determine in a better way how they interact with these methodologies.

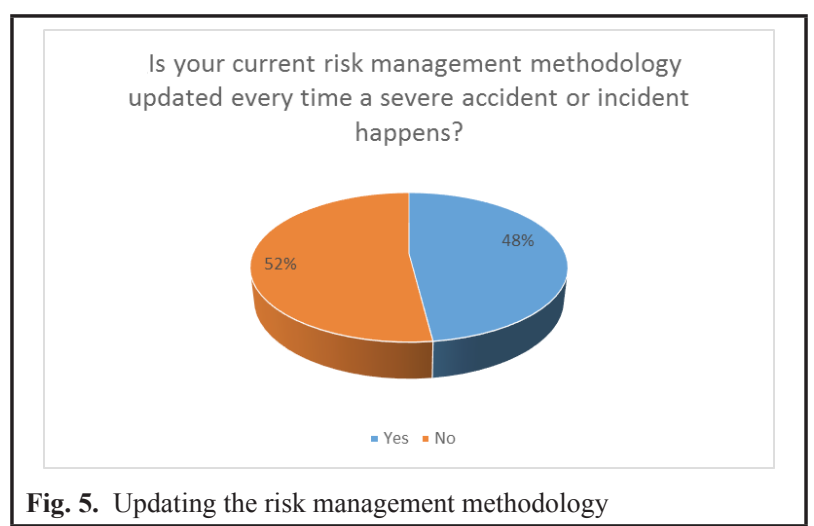

It is important that health service providers are aware of the safety of medical devices that are marketed in the country, being up to date with the most recent information that usually influences the decisions of the institutions, which can range from the acquisition of new technologies, or, if necessary, the decomissioning of devices that may put the patient at risk. This is why the surveyed were asked if they refer to the alarms issued on this matter whether at national or international level. All institutions answered that they mainly followed the alerts of INVIMA, followed by those of the FDA ( 9 institutions) and the WHO (6 institutions).

It is important to note that, to a lesser extent, the Medicines and Healthcare Products Regulatory Agency (MHRA) is also referred to by 3 institutions, the Pan American Health Organization (PAHO), the Emergency Care Research Institute (ECRI) in 2 institutions and national health surveillance agencies ANVISA (Brazil) and ANSM (France) in 1 institution. These results are shown in Fig. 6.

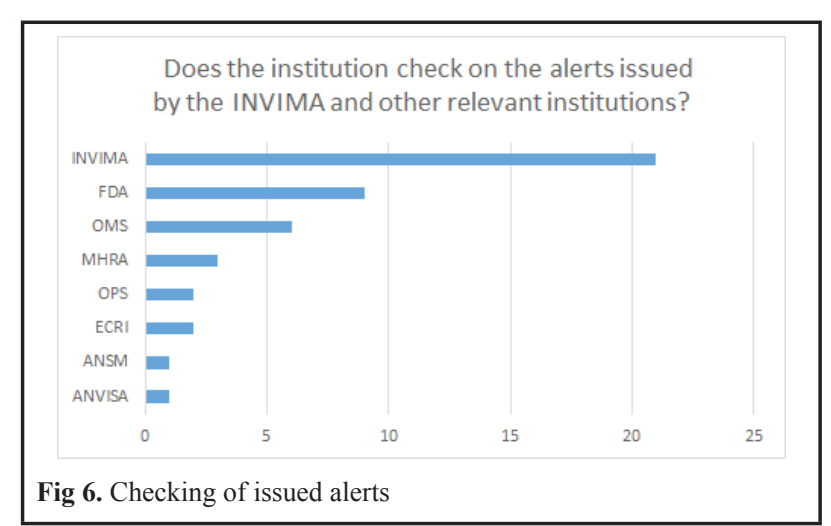

Another question of great interest was related to the times the technovigilance committee met in the year to analyze the reports issued in the different institutions, where $47.6 \%$ (10 institutions) report having met 0 to 3 times, whereas $23.8 \%$ (5 institutions) say they have met more than 10 times. In addition, $14.3 \%$ (3 institutions) have met from 4 to 7 times and $9.5 \%$ (2 institutions) from 8 to 10 times. In general, it can be observed that there is no defined standard as to the frequency in which the reports in the respective committees should be analyzed, being only clear the time in which the reports should be sent to INVIMA or to the regional secretaries according to whether there are serious adverse events to reporto or not. These results are shown in Fig. 7.

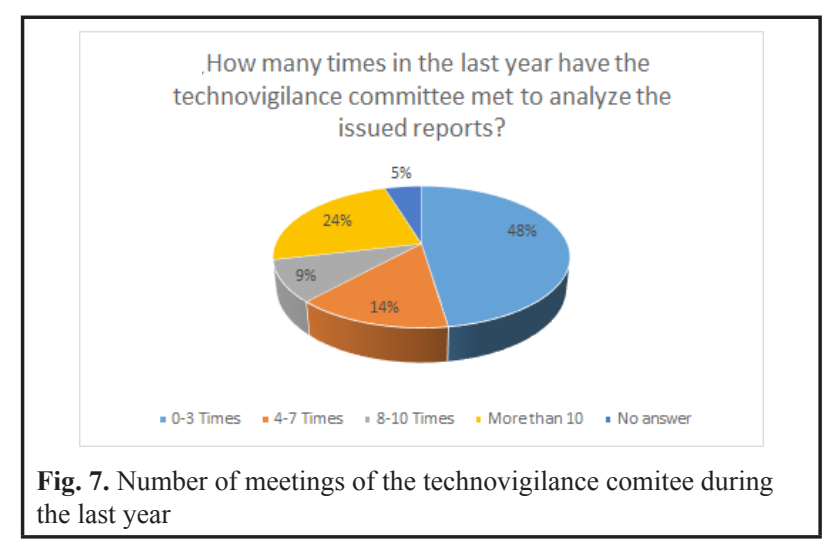




\section{DisCuSSION}

The first thing to note is the fundamental role of biomedical engineers in hospital institutions, since these professionals have a great responsibility for both reactive and proactive technovigilance activities and are involved in a direct way in the planning, management and execution of actions aimed at the safety of the patient and the people in contact with biomedical technology.

Regarding the answers given to the questions with a focus on reactive technovigilance, these show that most institutions are aware of the current legal regulations and, therefore, they report to INVIMA and the municipal secretaries within the deadlines. However, this is does not guarantee that all events and incidents occurred in these institutions have been reported internally, where the reasons for omission of these events may be due mainly to fear of punitive actions and the failure to reinforce the patient safety awareness that all members of the institutions must have.

It is also worth noting that it is a great step for clinical institutions in the southwest of the country to include a risk management system within the institutional programs of technovigilance, which shows that progress is being made in the area of proactive technovigilance. However, although it is understandable that this issue is in the process of improvement in most health care providers nationwide for what has been less than a decade in Colombia, it would be advisable for institutions to start applying the FMEA methodology, given that it has already been studied and established as the most recommended under the current national context.

Likewise, it is important to continue using training as a fundamental strategy to contribute to the proactive approach, which as evidenced only in some institutions is carried out in a continuous and periodic manner, and in turn should continue to be strengthened, ranging from the management of different biomedical technologies to the practice of reporting, which is still a weak link in patient safety.

Additionally, it was possible to show that some institutions are using as a reference not only national but also international agencies, which is a great advantage since it gives a greater view as to what currently exists in all matters relating to inspection, vigilance and control of the technologies that are coming to market worldwide. This is why it is recommended that more institutions do this work, which would allow them to access valuable information that can help them to have better criteria in the decision making regarding the actions and improvement plans to be carried out in the event of any problems related to technovigilance.

\section{Conclusion}

Institutions should adopt and address technovigilance not with the objective of only complying with the minimum requirements required by law, but as an opportunity for constant improvement and as a method to strengthen the safety of their patients.

In addition, the technovigilance program must be implemented in such a way that all those involved in the process are clear about the importance of their participation and the actions that must be taken so that they do not only participate reactively but also proactively, where being aware of the risks and putting barriers to prevent them must always be a fundamental task.

Although several institutions have already adopted a technovigilance program encompassing a clinical risk management system, there is still evidence of the need to identify and work on the risks involving staff in all the areas that comprise them, in order to do an adequate search for actions aimed at preventing and managing risks that may arise from the use and management of the technology.

Finally, it is not enough to rely on the institutional technovigilance program or the existence of a clinical risk management system. In addition to this, it is vital to train staff to reinforce patient's safety awareness, in subjects such as the correct management of biomedical devices and the reporting of adverse events to allow the institution to take the necessary and appropriate measures so that these events are not repeated.

\section{ACKNOWLEDGMENT}

Thanks to all the institutions from the Southwest Node of the Colombian Clinical Engineering network that participated in our survey.

\section{REFERENCES}

[1]. ABC de Tecnovigilancia. Accesed May 2016. [online]. https:// www.invima.gov.co/images/pdf/tecnovigilancia/ABC $\% 20$ Tecnovigilancia\%20INVIMA.pdf.

[2]. Guidance for Industry. Q9 Quality Risk Management. U.S. Department of Health and Human Services. Food and Drug Administration. June 2006.

[3]. Medical devices: guidance document. Classification of medical devices. European Commission. DG Health and Consumer. Directorate B, unit B2 "cosmetics and medical devices". MEDDEV 2. 4/1 Rev. 9 June 2010.

[4]. ISO 31000:2009. Risk management -- Principles and guidelines. November 2009 
[5]. ISO 14971:2007. Medical devices -- Application of risk management to medical devices. March 2003.

[6]. Sistemas de Gestión de Riesgo Clínico: Metodología AMFE. Accesed August 2016. [online]. https://www.invima. gov.co/images/pdf/tecnovigilancia/memorias/SISTEMAGESTI $\%$ C3\%93N\%20RIESGO $\% 20 \mathrm{CL} \% \mathrm{C} 3 \% 8 \mathrm{DNICO} \% 20-\% 20$ AMFE.pdf

[7]. Protocolo de Londres. Accessed August de 2016. [online] https:// www.minsalud.gov.co/sites/rid/Lists/BibliotecaDigital/RIDE/ DE/CA/PROTOCOLO_DE_LONDRES_INCIDENTES $\% 20$ CLINICOS.pdf.

[8]. Instituto Nacional de Seguridad y Salud en el Trabajo "NTC 679"

[9]. Resolución 4816 de 2008, "Por el cual se reglamenta el Programa Nacional de Tecnovigilancia", Colombia

[10]. K. Ishikawa, Guide to Quality Control. Tokio, Japón. Asian Productivity Organization, 1976.

[11]. República de Colombia. Instituto Nacional de Vigilancia de Medicamentos y Alimentos (INVIMA). Manual operativo ajustado a los resultados para la aplicación de la metodología análisis modo falla efecto - AMFE como herramienta de tecnovigilancia proactiva en las instituciones hospitalarias del país. https://www.invima.gov.co/images/pdf/tecnovigilancia/ memorias/MANUAL $\% 20$ OPERATIVO $\% 20$ VIGILANCIA $\% 20$ PROACTIVA.pdf 